\title{
Editor's Note: Global Modernities
}

This issue of DRJ explores how dance in transnational perspective alters our perspective on modernity. Dance participates in what Arjun Appadurai has called "diasporic public spheres" that are "one special diacritic of the global modern" $(1996,11)$. One's view of modernity derives at least in part from one's position on the global map. But, contemporary realities of deterritorialization complicate the very notion of positionality. Contributors to this issue reveal what we might call an alternative modernity of dance-or dance as an alternative modernity-composed within the crucible of diverse forms of migration, complex patterns of cultural heterogeneity at specific local sites, unexpected conglomerations of homogeneity and/or hybridity, and pressured reconfigurations of modernity in the media (particularly in television, which plays a role in several of these articles). All these variables have been broadly qualified by Appadurai as the contemporary "ethnoscape," and are addressed in this issue of $D R J$ from within the "cultural economy" of dance as movement. ${ }^{1}$ How dance moves through the world is a question not only of how dance is presented, mobilized, funded, or improvised under difficult circumstances, but how dance constitutes the global public sphere itself. For our authors, danced movement is not merely an abstract figure of relations in the global context, but rather sets of specific practices that beckon us to reformulate what we mean by modernity in and as movement, which also entails interpreting the political, social, and aesthetic roles choreographic performance has played since the 1970s and continues to play today.

Ananya Chatterjea's "On the Value of Mistranslations and Contaminations: The Category of 'Contemporary Choreography' in Asian Dance” examines the field of contemporary Asian dance in international fora, the mediascape, to speak like Appadurai whom Chatterjea cites, through which Asian dance circulates globally. Sensitive to the translation of South Asian cultural particularism driving the choreography of contemporary Asian artists into the modern/postmodern look fostered by international festivals, Chatterjea places contemporary Asian choreographic production within the context of global capitalism, according to which the work of Asian choreographers must "translate" into postmodern koiné. While encouraging the dissemination of work stemming from local dance traditions, Chatterjea argues for mistranslation and contamination on the global stage. Her article speaks to the global migration of dance as performative capital, and to how tradition should or should not be translated to establish an intercultural encounter within contemporary creativity and production. Chatterjea attests to translations of particular Asian movement traditions into a universalized "contemporary" vernacular, but, also, to translations of the universal "contemporary" vernacular back into indigenous styles. Hence, it is difficult to read exclusion into inclusion, or to politicize and historicize what Chatterjea calls "the flattened plane of global circulation" (10). We are left with a "domesticated diversity" (11).

Clare Croft's "Dance Returns to American Cultural Diplomacy: The U.S. State Department's 2003 Dance Residency Program and Its After Effects" explores the international context through an intercultural collaboration rather than-as in Chatterjea's piece-as an issue of translation. Croft focuses on the creation and presentation of A Slipping Glimpse, involving Indian and American artists Tansuree Shankar and Margaret Jenkins that was part of a post-9/11 initiative of American state-sponsored cultural diplomacy. Croft explores how such programs actually engender 
relationships, and how the artists involved are creative in coping with programmatic insufficiencies. She also calls attention to structural inequalities between the U.S. and South Asian participants that transpire in the process of artistic composition, including authorship and choreographic choices, actual participation of Indian dancers in rehearsals and performances, etc. The framework of diplomacy is radically reconsidered in light of the necessity to form long-term creative and cooperative relationships.

Rachel Fensham's “'Breakin' the Rules': Eleo Pomare and the Transcultural Choreographies of Black Modernity" turns our attention to the well known yet largely misrecognized and widely misunderstood dancer and choreographer Eleo Pomare. De-emphasizing Pomare's career in New York as the angry young man of the Black Arts Movement, Fensham focuses instead on Pomare's work in the early 1960s in Amsterdam and in the early 1970s in Melbourne. Drawing upon Fred Moten's theory of the cut from his book In the Break, Fensham locates Pomare's choreography in a radical black avant-garde tendency that has not been adequately recognized by the North American dance establishment. This, in turn, leads Fensham to posit Pomare's "expanded legacy" within "a transnational aesthetics of dance modernity." Fensham's article, one of the first important scholarly investigations of Pomare, throws a new light on the meaning of dance modernism from the perspective of his global sites of creative endeavor and intervention beyond the framework of his New York City dance career in the 1960s.

In "Mobilizing Dance/Traumatizing Dance: Kongonya and the Politics of Zimbabwe," Jairos Gonye discusses dance in Zimbabwe during the 1970s war for independence. The dance called kongonya is by turns traumatizing and tranquilizing; at once spiritualizing and patriotic, and an incitement to physical violence, as well as an instrument of control in the service of the state. Through his personal experience as a child at all-night outdoor political meetings (pungwe), interviews with his contemporaries, and his own witnessing of Zimbabwean cultural politics over the last thirty years, Gonye analyzes kongonya-once instrumental in winning the war of liberation-as prone to political manipulation through distortion not only of the more standard cultural functions of dance, but of the dancers themselves who perform it as political actors. The thick description of kongonya enables Gonye to provide a micro-historical account of a dance as political education, an expression of patriotism, and a form of hypnosis as well as of pacification. From there, he launches into a critique of its uses in post-2000 Zimbabwean politics, especially with respect to the galas broadcast on television. The perspectives Gonye affords on dance, mobilization, war, and political manipulation are multifaceted, and bring us—as does Fensham's article—back to the 1970s.

Ahalya Satkunaratnam's “Staging War: Performing Bharata Natyam in Colombo, Sri Lanka” extends the thematics of dance and war into the more contemporary framework of Sri Lanka during its ethnically divisive civil war in its final years (2005-2007). Satkunaratnam focuses on the efforts of a female Tamil choreographer Janiki through a subtle intracultural use of Bharata Natyam to stage identity, and gesture toward healing the cultural conflict between Tamil and Sinhalese populations in wartorn Sri Lanka. Given the commingling of Sinhala and Tamil culture, such that Kandyan and Bharata Natyam also have commonalities, Satkunaratnam emphasizes the constructed nature of ethnic identity in Colombo. Yet, it is these commonalities that are put into question by ethnic strife, in the face of which Janiki deploys traditional narrative choreography drawn from the Mahabarata, yet also innovates to offer a vision of multiculturalism both theatrically and performatively.

The thematic coherency of this issue results from the submissions themselves, and is an editorial response to a set of related concerns. I wish to call the reader's attention to two calls for formally conceived special issues of $D R J$ in the near future. And, I wish to thank Sardono Kusomo for permission to use an image of his Sunken Seas on the cover of this issue.

Mark Franko

Editor, Dance Research Journal 


\section{Note}

1. Appadurai speaks of "the cultural economy of a world in motion" $(1996,202)$.

\section{Work Cited}

Appadurai, Arjun. 1996. Modernity at Large. Minneapolis, MN: University of Minnesota Press.
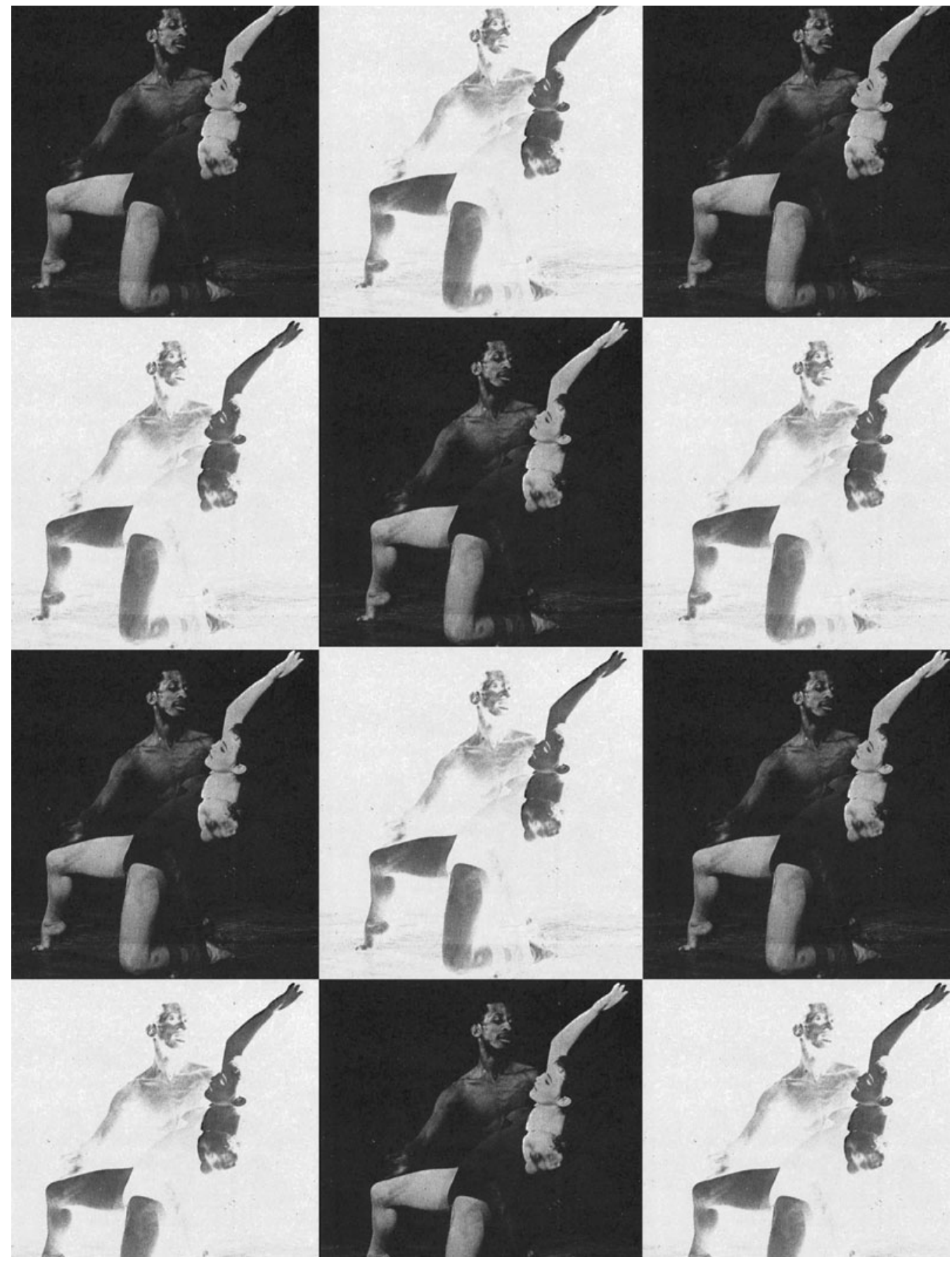